\title{
MONITORING CHEMOTHERAPY-INDUCED ALOPECIA WITH TRICHOSCOPY
}

CARO G, ROSSI A., FORTUNA MC., PIGLIACELLI F., D'ARINO A., CARLESIMO M.

\section{BACKGROUND}

Chemotherapy-induced alopecia (CIA) has overall incidence is $65 \%$, nevertheless to date no fully satisfactory cure is at hand. It may occur 2 weeks (anagen effluvium) or months (telogen effluvium) after starting chemotherapy, and it is usually reversible in 3-6 months. Trichoscopy is an effective, non-invasive and non-expensive method, largely employed for scalp evaluation, but no description of CIA trichoscopic pattern are actually present in literature.

The aim of this study is to describe CIA trichoscopic pattern, and their modifications during the different phases of chemotherapy.

\section{MATERIALS AND METHODS}

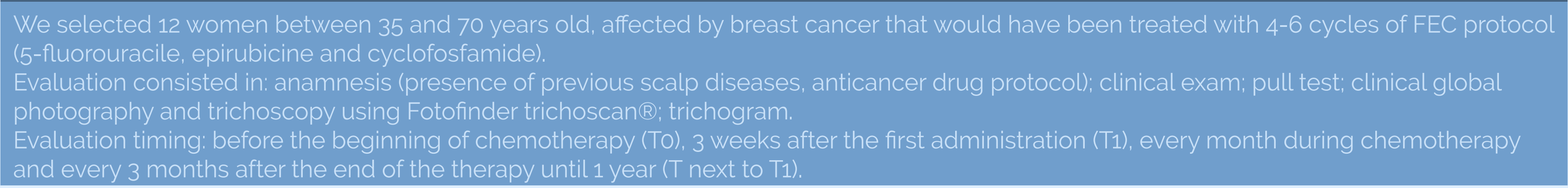

\section{RESULTS}

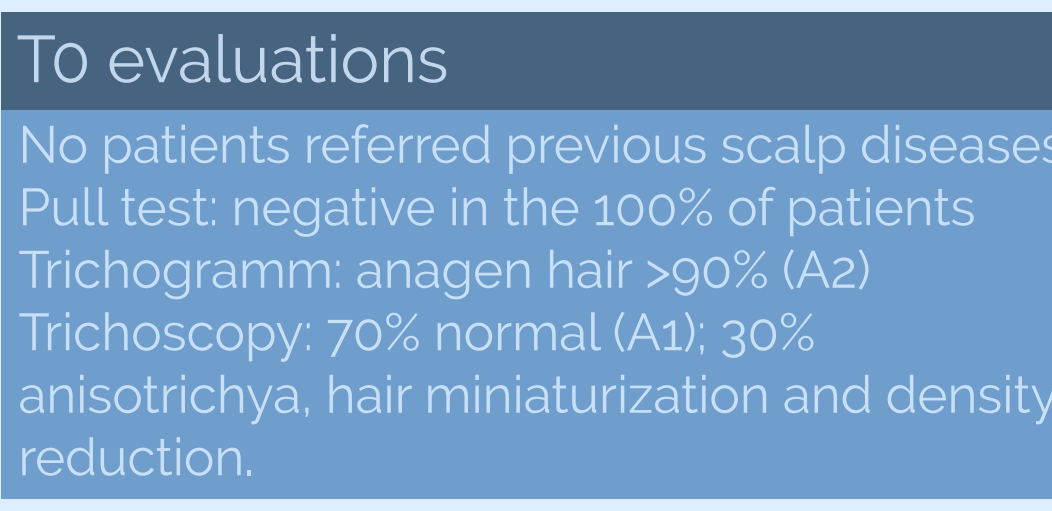

T>1
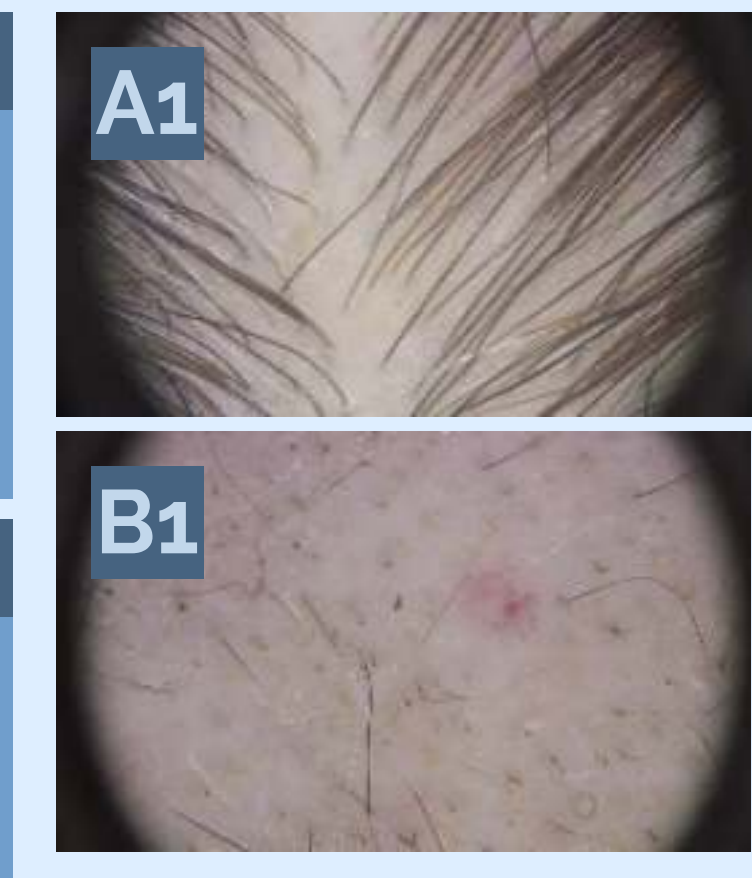
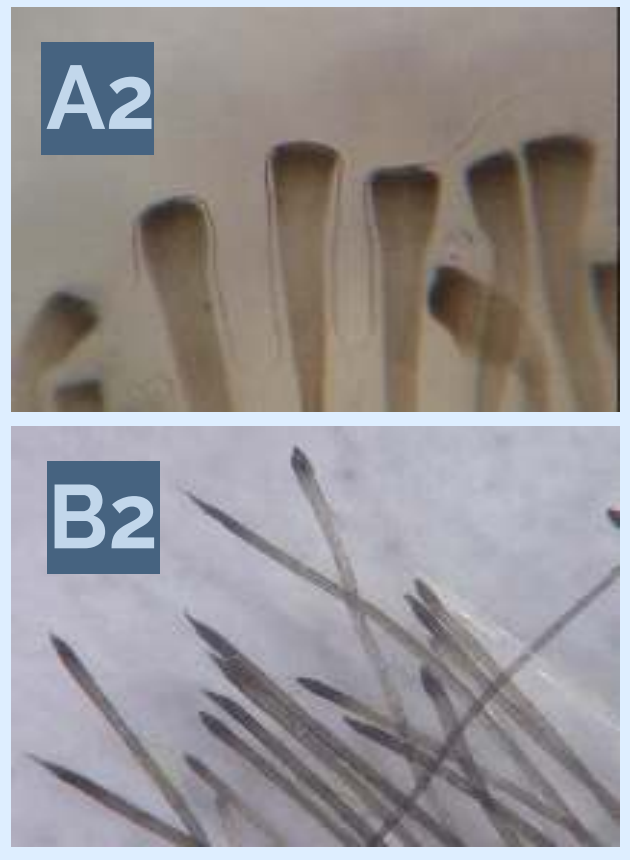

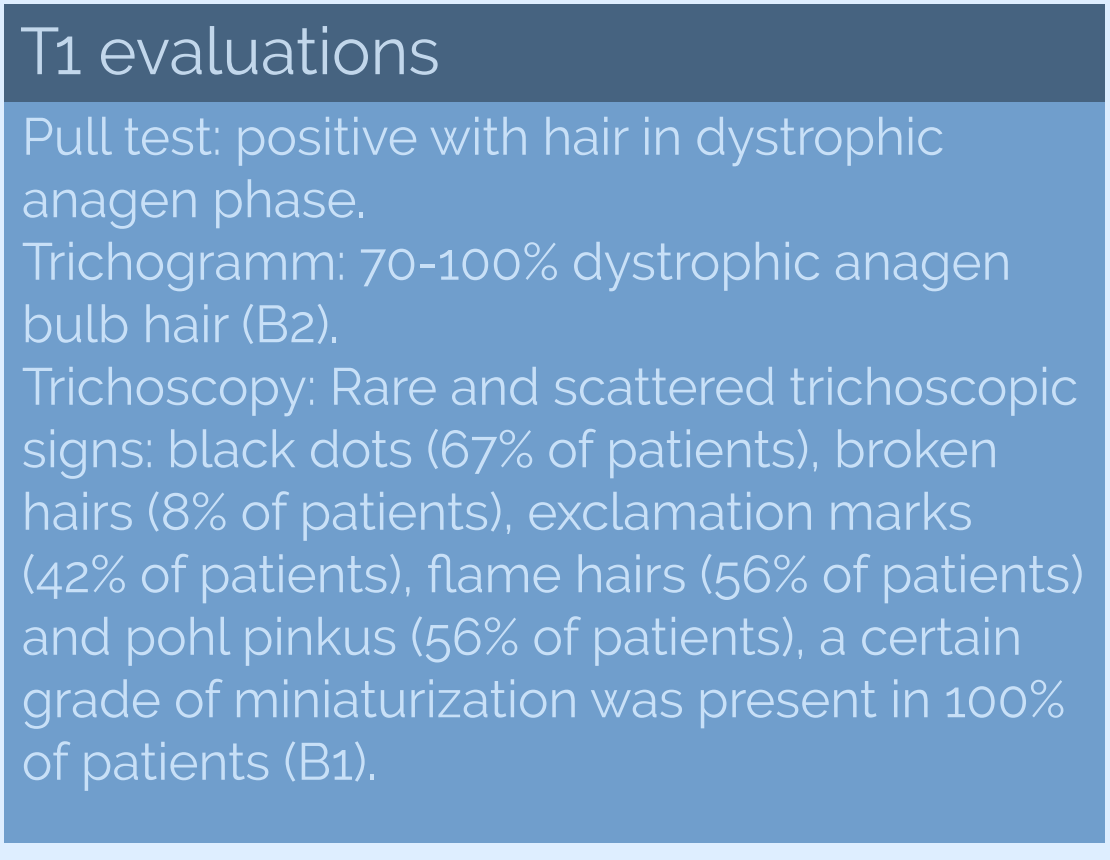

\begin{tabular}{ccc} 
PATIENTS & $\begin{array}{c}\text { CIRCLE } \\
\text { HAIR }\end{array}$ & $\begin{array}{c}\text { POHL } \\
\text { PINKUS }\end{array}$ \\
\hline $\mathbf{1}$ & 0 & 1 \\
$\mathbf{2}$ & 0 & 1 \\
$\mathbf{3}$ & 1 & 0 \\
$\mathbf{4}$ & 0 & 1 \\
$\mathbf{5}$ & 0 & 0 \\
$\mathbf{6}$ & 0 & 0 \\
$\mathbf{7}$ & 1 & 1 \\
$\mathbf{8}$ & 1 & 1 \\
$\mathbf{9}$ & 1 & 0 \\
$\mathbf{1 0}$ & 0 & 1 \\
$\mathbf{1 1}$ & 0 & 1 \\
$\mathbf{1 2}$ & 0 & 0 \\
& $33 \%$ & $58 \%$
\end{tabular}

$\begin{array}{cccc}\text { EXCLAMATI } & \begin{array}{c}\text { BLACK } \\ \text { ON MARKS }\end{array} & \begin{array}{c}\text { FLAME } \\ \text { DAIR }\end{array} & \begin{array}{c}\text { DENSITY } \\ \text { REDUCTION }\end{array} \\ 1 & 1 & 1 & 0 \\ 0 & 1 & 1 & 1 \\ 0 & 0 & 0 & 0 \\ 0 & 1 & & 1 \\ 0 & 0 & 0 & 0 \\ 1 & 1 & 1 & 1 \\ 0 & 1 & 1 & 1 \\ 1 & 1 & 1 & 1 \\ 0 & 0 & 0 & 1 \\ 1 & 1 & 1 & 1 \\ 0 & 1 & 1 & 1 \\ 1 & 0 & 0 & 1 \\ 42 \% & 67 \% & 67 \% & 75 \%\end{array}$

EMPTY
FOLICL
1
1
0
1
0
1
1
1
0
1
1
1
$75 \%$
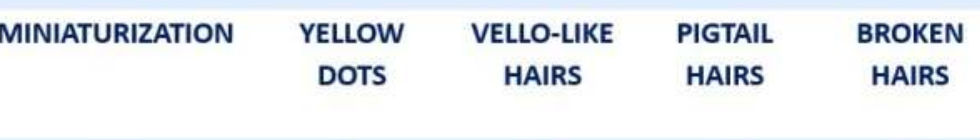

$\begin{array}{cccccc}1 & 1 & 1 & 1 & 0 & 0 \\ 1 & 1 & 1 & 1 & 1 & 0 \\ 0 & 1 & 0 & 1 & 1 & 0 \\ 1 & 1 & 1 & 1 & 0 & 0 \\ 0 & 1 & 0 & 1 & 0 & 0 \\ 1 & 1 & 1 & 1 & 0 & 0 \\ 1 & 1 & 1 & 1 & 1 & 1 \\ 1 & 1 & 1 & 1 & 1 & 1 \\ 0 & 1 & 0 & 0 & 0 & 0 \\ 1 & 1 & 1 & 1 & 0 & 0 \\ 1 & 1 & 1 & 0 & 1 & 0 \\ 1 & 1 & 1 & 1 & 0 & 0 \\ 75 \% & 100 \% & 75 \% & 92 \% & 42 \% & 8 \%\end{array}$
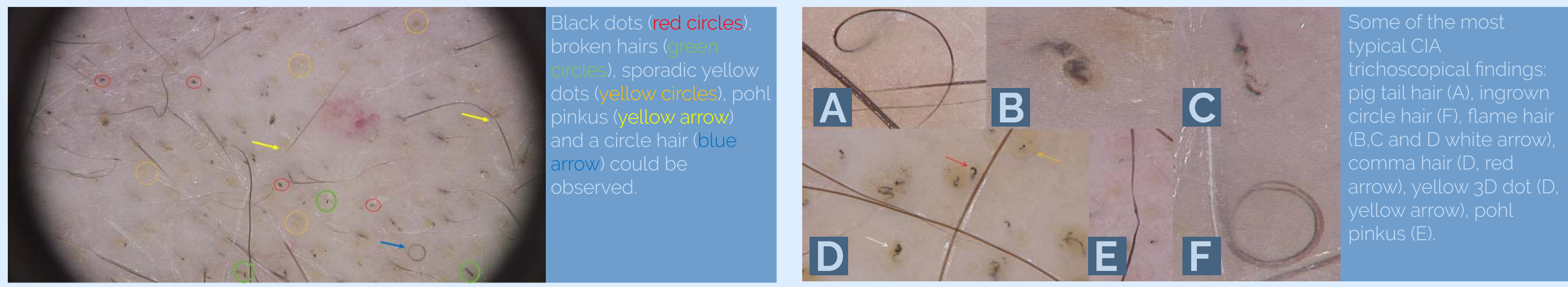

\section{THREE MONTHS AFTER THE END OF CHEMOTHERAPY}

Trichogram: increase of anagen hair, reduction or disappearance of dystrophic anagen hair, absence of telogen hair Trichoscopy: progressive increase of active follicular units and elongation of the existing hair.

$80 \%$ of patients' new hair were hyperpigmented and thicken $(56 \%)$ or thinner $(44 \%), 80 \%$ had a different pigmentation.

$20 \%$ of all patients reported a not complete regrowth.

\section{CONCLUSIONS}

This study produces a description of CIA trichoscopic pattern and its evolution during the different phases, in order to indicate which are the most important moments that have to be monitored.

More studies have to be conducted to better characterize this type of alopecia, and continuous attention must be paid to this signs, in order to establish a connection with hair loss phase. 